\title{
Diabetes Mellitus, Smoking, and the Risk for Asymptomatic Peripheral Arterial Disease: Whom Should We Screen?
}

\author{
Sharon L. Eason, MPH, Nancy J. Petersen, PhD, Maria Suarez-Almazor, MD, PhD, \\ Barry Davis, MD, PhD, and Tracie C. Collins, MD, MPH
}

Objective: To describe coexisting medical conditions and lifestyle factors associated with asymptomatic peripheral arterial disease (PAD) in a population of white, African American, and Hispanic patients.

Study Design and Setting: White, African American, and Hispanic patients 50 years or older were recruited for this cross-sectional study from 4 primary care clinics in Houston, TX. Patients with an ankle-brachial index (ABI) $<0.9$ and without leg symptoms typical of PAD were diagnosed with asymptomatic PAD.

Results: 403 patients were screened for PAD. Of these, 25 (6.2\%) had asymptomatic PAD. Compared with patients without PAD, diabetes mellitus ([OR] 3.8; 95\% CI 1.6, 9.0) and a history of smoking at least 1 pack of cigarettes per day $([\mathrm{OR}] 2.5 ; 95 \% \mathrm{CI} 1.1,6.0)$ were significantly associated with asymptomatic PAD. An interaction effect existed between diabetes mellitus and smoking at least 1 pack of cigarettes per day. Diabetes mellitus combined with heavy smoking showed the highest predicted value positive (15\%) and the highest specificity (92\%). A lack of both demonstrated low rates for predicting asymptomatic PAD (predicted value positive, 1\%).

Conclusion: The ankle-brachial index could become routine screening among patients with diabetes mellitus and/or who smoke. (J Am Board Fam Pract 2005;18:355-61.)

Among patients aged 50 years and older, the prevalence of peripheral arterial disease (PAD) for both symptomatic and asymptomatic patients is $12 \%$ to $19 \% .{ }^{1-4}$ Previous research has outlined risk factors associated with PAD, which include diabetes mel-

Submitted, revised, 25 March 2005.

From the Houston Center for Quality of Care and Utilization Studies, Houston Veterans Affairs Medical Center, Section of Health Services Research, Baylor College of Medicine (SLE, NJP, MS-A, TCC), Houston, TX; and The University of Texas School of Public Health (BD), Houston, TX.

Funding: This material is the result of work supported with resources and the use of facilities at the Houston Center for Quality of Care and Utilization Studies, Houston Veterans Affairs Medical Center. TCC was a recipient of a Robert Wood Johnson Minority Medical Faculty Development Award at the time this work was completed and funding from this award also provided support for this project.

Conflict of interest: none declared.

Corresponding author: Tracie C. Collins, MD, MPH, or Sharon Eason, MPH, Houston Center for Quality of Care and Utilization Studies (Veterans Affairs Medical Center), 2450 Holcombe Blvd. Suite 01Y (152), Houston, TX 77021 (e-mail: tcollins@bcm.tmc.edu or season@bcm.tmc.edu).

The views expressed in this article are those of the authors and do not necessarily represent the views of the Department of Veterans Affairs. The results of this study were presented as a poster at the Society of General Internal Medicine conference in Vancouver, BC, Canada, May 1st, 2003. litus, hypertension, older age, and dyslipidemia. ${ }^{1-17}$ A higher prevalence of PAD has also been found among older African Americans and Hispanics when compared with whites. ${ }^{11,12}$

Research has shown that $53.8 \%$ of patients with $\mathrm{PAD}$ within a general medicine practice are asymptomatic. ${ }^{13}$ The inadequate recognition of PAD may place many patients at risk of its complications, including ischemic ulceration, gangrene, limb loss, and/or increased cardiovascular morbidity and mortality. ${ }^{5,14}$ As Hirsch demonstrated in a large study in 2001, the under-utilization of early screening and diagnosis of PAD could be a barrier to preventing further cardiovascular risk. ${ }^{18} \mathrm{In}$ creasing physicians' awareness of the importance of screening patients at high risk for $\mathrm{PAD}$ has important benefits. Patients treated early for PAD could have a significantly improved quality of life as well as the decreased likelihood of future cardiovascular morbidity and mortality.

The purpose of this study was to describe coexisting medical conditions and lifestyle factors associated with asymptomatic PAD in a population of white, African American, and English- and Spanishspeaking Hispanic patients attending a primary care clinic. 


\section{Methods}

This study was based on a subgroup analysis of a previously identified PAD cohort. Data were collected as part of a cross-sectional study on the epidemiology of $\mathrm{PAD}$ among whites, African Americans, and English- and Spanish-speaking Hispanics. It obtained equal representation of 3 ethnic groups to assess the prevalence of PAD by race. The study took place between September 2000 and August 2001 and was approved by the Institutional Review Board for Human Subjects Research for Baylor College of Medicine and Affiliated Hospitals and by the Department of Veterans Affairs (VA) Research and Development Committee. Written informed consent was obtained from all patients.

\section{Study Population}

All patients attended one of 4 primary care clinics in Houston, TX: Martin Luther King Clinic, the primary care clinics at the Michael E. DeBakey Veterans Medical Center (formerly the Houston VA Medical Center), and the primary care clinics at Ben Taub Hospital (later to be replaced by Gulfgate Clinic because of feasibility of recruitment). Martin Luther King Clinic, Ben Taub Hospital, and Gulfgate Clinic were affiliated with the Harris County Hospital District (HCHD) and served lower income patients from racially diverse backgrounds. Patients who identified their ethnicity as non-Hispanic white, African American, or Hispanic were recruited. Both English- and Spanishspeaking Hispanics were eligible for participation in the study. Subjects were consecutively identified using patient appointment lists and were then telephoned at home or approached in the clinic. A research assistant determined further eligibility for the study, and patients gave informed consent for study participation.

\section{Exclusion Criteria}

The study initially included all men and women older than 50 years. However, after finding no patients with an ankle-brachial index (ABI) of less than 0.90 between the ages of 50 and 54, the recruitment age was increased to 55 years and older. Those patients aged 50 to 54 years were not excluded from the analyses. Patients unable to read or speak English or Spanish were excluded. Patients were also excluded if there was a history of demen- tia, chronic obstructive pulmonary disease requiring oxygen, a malignancy other than skin (with a probability of survival of less than 6 months or with a recent diagnosis), leg ulcers or gangrene, or a lower extremity amputation. Patients were also excluded from participating if they were unable to provide a contact telephone number or if they resided outside of Texas. Patients with symptomatic PAD were excluded from the analysis, so that characteristics solely associated with asymptomatic disease could be determined.

\section{Data Collection Techniques and Instruments}

\section{Ankle-Brachial Index}

The ABI is the ratio of the systolic blood pressure in the ankle to that in the arm. The ABI measurement was obtained by a research assistant trained at the Houston VA Medical Center vascular laboratory. The ABI and questionnaires were performed in the clinic room before the patient's scheduled appointment with the physician. The patient was asked to lay supine for 5 minutes before the ABI was measured, to assure an accurate blood pressure reading. Blood pressure cuffs were placed on the arms and ankles, and the pulse was detected with an ultrasound Doppler. The systolic pressure was taken in the arm and the dorsalis pedis (DP) and posterior tibialis (PT) pulse of the ankle. The pressures were always taken in the following order: right arm, right $\mathrm{DP}$, right $\mathrm{PT}$, left $\mathrm{PT}$, left $\mathrm{DP}$, left arm. The higher of the DP and PT measurements in each ankle was taken again and recorded. The highest arm systolic pressure was remeasured if it was at least $10 \mathrm{~mm} \mathrm{Hg}$ higher than the systolic pressure in the other arm. To calculate the ABI, the average of the 2 highest of the 3 pressures taken in the ankle was divided by the average of the arm systolic pressures (or the average of the highest 2 if a third pressure was taken). A patient with an ABI of $<0.9$ was classified as having $\mathrm{PAD}$, as many studies have found that a ratio of $\leq 0.90$ signifies the presence of PAD. ${ }^{19-24}$

\section{San Diego Claudication Questionnaire}

The San Diego Claudication Questionnaire (SDCQ), a self-administered questionnaire developed by Criqui et al, ${ }^{1}$ was given to determine classic intermittent claudication, atypical leg symptoms, or no leg symptoms. Within this study, we defined asymptomatic $\mathrm{PAD}$ as patients with an $\mathrm{ABI}$ of $<0.9$ and no leg symptoms per the SDCQ. 


\section{Lifestyle and Clinical Survey}

The Lifestyle and Clinical Survey was developed and validated by Dr. Tracie Collins, the principal investigator on the study. ${ }^{25}$ It involved 88 items that identified patient sociodemographics, a history of heart failure, hypertension, diabetes, medication use, and social habits (eg, smoking, physical activity). The survey required approximately 10 minutes to administer.

\section{Statistical Analysis}

The $\chi^{2}$ for dichotomous variables determined significant univariate associations. The dependent variable was the presence of asymptomatic PAD, and the independent variable was the medical condition or lifestyle factor in question. Multivariate logistic regression determined the association between the independent variables and asymptomatic PAD.

The following independent variables were included in a logistic regression model: race (white, African American, or Hispanic); age (continuous); if the patient reported that their physician had ever diagnosed them with hypertension, congestive heart failure, and/or diabetes mellitus (yes/no); if the patient currently consumed alcoholic beverages (yes/no); if the patient did consume alcohol, how often he or she consumed alcohol (rarely/occasionally or daily/weekly); if the patient smoked at least 100 cigarettes in his or her lifetime (yes/no); if the patient smoked 100 cigarettes in his or her lifetime, then the average number of cigarettes the patient smoked per day (less than 1 pack per day, at least 1 pack per day); the number of years the patient smoked on average in his or her lifetime (0 years, less than 1 year to 40 years, greater than 40 years); how often the patient walked for at least 10 minutes without stopping (rarely or never, 1 time per week, more than 1 time per week). All analyses were performed using SAS 6.0 for PC and SAS 8 for UNIX.

\section{Results}

457 patients were approached for study participation, and 403 agreed to participate. According to the SDCQ, 212 patients experienced leg symptoms on exertion and 191 were asymptomatic. Of the 403, 62 patients $(15 \%)$ had a measured $\mathrm{ABI}<0.9$. Of those with PAD, 25 (40\%) were asymptomatic. Ultimately, $6.2 \%$ of patients screened in the primary care clinics had asymptomatic PAD.

General characteristics of the study population are presented in Table 1 . Of the 25 patients with PAD, 36\% were white, 36\% were African American, $28 \%$ were Hispanic, and $40 \%$ were female. The mean age of the entire cohort was 63.6 years (SD, 7.24). This study found that asymptomatic $\mathrm{PAD}$ did not differ in prevalence by race.

Hypertension was reported in $80 \%$ of patients with asymptomatic $\mathrm{PAD}$ and in $66 \%$ of the patients without PAD $(P>.05)$. Congestive heart failure was reported in $12 \%$ of patients with asymptomatic PAD versus $5 \%$ of patients without $\mathrm{PAD}(P>.05)$. The prevalence of diabetes mellitus was significantly higher in patients with asymptomatic PAD when compared with patients without PAD (64\% vs. $34 \%$, respectively; $P<.05$ ).

Table 1. General Characteristics of the Study Population

\begin{tabular}{|c|c|c|c|}
\hline & $\begin{array}{c}\text { Without } \text { PAD* }^{*}(\mathrm{n}=341) \\
\text { N }(\%)\end{array}$ & $\begin{array}{c}\text { With Asymptomatic PAD }(\mathrm{n}=25) \\
\text { N }(\%)\end{array}$ & $P$ Value \\
\hline $\begin{array}{l}\text { Gender, no. } \\
\text { Male } \\
\text { Female }\end{array}$ & $\begin{array}{l}159(47) \\
177(53)\end{array}$ & $\begin{array}{l}15(60) \\
10(40)\end{array}$ & .30 \\
\hline $\begin{array}{l}\text { Race/ethnicity } \\
\text { White } \\
\text { African American } \\
\text { Hispanic }\end{array}$ & $\begin{array}{l}121(93) \\
106(92) \\
114(94)\end{array}$ & $\begin{array}{l}9(36) \\
9(36) \\
7(28)\end{array}$ & .66 \\
\hline $\begin{array}{l}\text { Comorbidities } \\
\text { Hypertension } \\
\text { Congestive heart failure } \\
\text { Diabetes }\end{array}$ & $\begin{array}{c}226(66) \\
15(5) \\
116(34)\end{array}$ & $\begin{array}{r}20(80) \\
3(12) \\
16(64)\end{array}$ & $\begin{array}{l}.19 \\
.11 \\
.00\end{array}$ \\
\hline Mean age in years (SD) & $63.54(7.3)$ & $64.56(6.4)$ & .62 \\
\hline Age range in years & $50-90$ & $50-74$ & \\
\hline
\end{tabular}

* PAD, peripheral arterial disease. 


\begin{tabular}{|c|c|c|c|c|}
\hline & $\begin{array}{l}\text { Without } \\
\text { PAD* } \\
\text { N }(\%)\end{array}$ & $\begin{array}{l}\text { With Asymptomatic } \\
\text { PAD } \\
\text { N }(\%)\end{array}$ & $P$ Value & Total \\
\hline $\begin{array}{l}\text { Have you smoked at least } 100 \text { cigarettes in your entire life? } \\
\text { Yes } \\
\text { No }\end{array}$ & $\begin{array}{l}183(54) \\
157(46)\end{array}$ & $\begin{array}{l}15(60) \\
10(40)\end{array}$ & .55 & $\begin{array}{l}198(54) \\
167(46)\end{array}$ \\
\hline $\begin{array}{l}\text { If you smoke, how many cigarettes have you smoked per day? } \\
1 \text { pack or less } \\
>1 \text { pack }\end{array}$ & $\begin{array}{r}133(72) \\
53(28)\end{array}$ & $\begin{array}{r}10(67) \\
5(33)\end{array}$ & .03 & $\begin{array}{r}143(71) \\
58(29)\end{array}$ \\
\hline $\begin{array}{l}\text { How many years have you been a regular smoker? } \\
0 \text { years } \\
<1 \text { year to } 40 \text { years } \\
>40 \text { years }\end{array}$ & $\begin{array}{r}197(58) \\
75(22) \\
69(20)\end{array}$ & $\begin{array}{r}13(52) \\
6(24) \\
6(24)\end{array}$ & .84 & \\
\hline $\begin{array}{l}\text { Do you drink alcoholic beverages? } \\
\text { Yes } \\
\text { No }\end{array}$ & $\begin{array}{l}119(35) \\
222(65)\end{array}$ & $\begin{array}{r}4(16) \\
21(84)\end{array}$ & .05 & $\begin{array}{l}123(34) \\
243(66)\end{array}$ \\
\hline $\begin{array}{l}\text { How often do you consume alcohol? } \\
\text { Some } \\
\text { Weekly } \\
\text { Daily }\end{array}$ & $\begin{array}{l}23(19) \\
63(52) \\
35(29)\end{array}$ & $\begin{array}{l}1(25) \\
2(50) \\
1(25)\end{array}$ & .64 & $\begin{array}{l}24(19) \\
65(52) \\
36(29)\end{array}$ \\
\hline $\begin{array}{l}\text { How often do you walk for at least } 10 \text { minutes without stopping? } \\
\text { Rarely or never } \\
\text { Once/week or more }\end{array}$ & $\begin{array}{r}96(28) \\
245(72)\end{array}$ & $\begin{array}{l}12(48) \\
13(52)\end{array}$ & .31 & $\begin{array}{l}107(30) \\
258(70)\end{array}$ \\
\hline
\end{tabular}

* PAD, peripheral arterial disease.

Questions and results from the Lifestyle and Clinical Survey are presented in Table 2. A majority of both groups smoked at least 100 cigarettes in their lifetimes (54\% vs. $60 \%$ ). Compared with those who did not smoke, patients who smoked more than one pack of cigarettes per day showed a significantly higher association with asymptomatic $\operatorname{PAD}(P=.03)$. Rates did not differ significantly for number of years a patient regularly smoked $(P>$ $.05)$.

A majority of patients in both groups did not consume alcohol, and trended toward statistical significance $(65 \%$ without $\mathrm{PAD}$ vs. $84 \%$ with asymptomatic $\mathrm{PAD}, P=.05)$. How often patients consumed alcohol did not differ significantly by the presence or absence of asymptomatic PAD $(P>$ $.05)$. More patients with asymptomatic PAD rarely or never walked for at least 10 minutes without stopping ( $48 \%$ vs. $28 \%, P>.05$ ). The majority of patients in both groups walk at least once a week or more (52\% vs. $72 \%)$.

After adjusting for age and gender, diabetes mellitus and smoking at least 1 pack of cigarettes per day were significantly associated with asymptomatic $\mathrm{PAD}$ when compared with those without PAD. Patients with diabetes mellitus were 3.8 times (95\% CI 1.6, 9.0) more likely to have asymptomatic PAD than patients without diabetes mellitus. Patients who smoked at least 1 pack of cigarettes per day were 2.5 times (95\% CI 1.1, 6.0) more likely to have asymptomatic PAD than patients who did not smoke at least 1 pack of cigarettes per day.

Because diabetes mellitus and smoking at least 1 pack of cigarettes per day demonstrated the strongest associations with asymptomatic PAD, these factors were further examined to determine the presence of an interaction effect. Table 3 presents the sensitivities, specificities, and predicted values of diabetes mellitus and smoking as predictors of asymptomatic PAD. When examined individually, diabetes mellitus predicted asymptomatic PAD more sensitively than heavy smoking (64\%), and

Table 3. Predicting Asymptomatic PAD*

\begin{tabular}{lccrc}
\hline & $\begin{array}{c}\text { Sensitivity } \\
(\%) \dagger\end{array}$ & $\begin{array}{c}\text { Specificity } \\
(\%) \ddagger\end{array}$ & $\begin{array}{r}\text { PVP } \\
(\%) \S\end{array}$ & $\begin{array}{r}\text { PVN } \\
(\%)\end{array}$ \\
\hline Diabetes & 64 & 66 & 12 & 96 \\
Smoke & 34 & 46 & 8 & 94 \\
Both diabetes/smoke & 20 & 92 & 15 & 94 \\
Neither diabetes/smoke & 8 & 55 & 1 & 89 \\
\hline
\end{tabular}

* PAD, peripheral arterial disease.

† Sensitivity, the probability of a positive test result in patients with asymptomatic PAD.

$\ddagger$ Specificity, the probability of a negative test result in patients without PAD.

$\S$ PVP, probability of asymptomatic PAD given a positive test result.

$\|$ PVN, probability of no PAD given a negative test result. 
diabetes mellitus combined with heavy smoking demonstrated the highest positive predicted value $(15 \%)$ and the highest specificity (92\%). Not having diabetes mellitus combined with smoking less than a pack of cigarettes per day showed extremely low rates for predicting asymptomatic PAD (positive predicted value, $1 \%$ ). Figure 1 graphically presents the positive predicted values of diabetes mellitus and smoking with asymptomatic PAD. An interaction effect of diabetes mellitus and heavy smoking seems to exist in predicting asymptomatic PAD.

\section{Discussion}

This study found a $6.2 \%$ prevalence of asymptomatic $\mathrm{PAD}$ in a racially diverse population attending a primary care clinic. Patients with a history of diabetes mellitus and smoking at least one pack of cigarettes per day were more likely to have asymptomatic PAD. These results are comparable with those of previous studies on both symptomatic and asymptomatic PAD.9,15,19 These results build on previous ones by demonstrating the additive effects of risk factors that are associated with asymptomatic $\mathrm{PAD}$ - potentially highlighting criteria for screening.

The complications of diabetes mellitus vary widely, including PAD as one of many problems that can result. A cross-sectional study performed by Walters et $\mathrm{al}^{20}$ found an $8.7 \%$ prevalence of PAD among patients with type I diabetes mellitus and a $23.5 \%$ prevalence of PAD among patients with type 2 diabetes mellitus. Regardless of the high prevalence and complications that can result from $\mathrm{PAD}$, it is not yet common practice to routinely screen for the disease in patients with diabetes mellitus. Examining the results of this study and those of previous studies, perhaps the ABI should be part of a routine doctor's office visit for patients with diabetes mellitus.

A multitude of research has agreed on the strong association between cigarette smoking and PAD. ${ }^{2,13,15,19,26}$ Previously it has been found that current smoking status has a greater effect on PAD than a lifetime history of smoking, because it has been shown that smoking cessation significantly reduces cardiovascular complications. ${ }^{27-31}$ As this study focused on the patient's lifetime smoking history, it can only be inferred from our results that a history of heavy smoking is associated with asymptomatic PAD.

In our experience, general medical practices typically do not measure the ABI unless a patient begins to exhibit symptoms of the disease. Previous research has found that regardless of the presence or absence of symptoms, PAD can be reliably diagnosed with the ABI. Newman et $\mathrm{al}^{13}$ examined the association between $\mathrm{ABI}$ values and different leg symptoms associated with PAD. Looking at $\mathrm{ABI}$ measurements in increments of 0.10 , the findings suggested that asymptomatic cases of PAD predominated over symptomatic cases. In general, asymptomatic disease decreased in prevalence as $\mathrm{ABI}$ values decreased; the highest prevalence of a lack of symptoms existed in the "borderline" cases with an ABI of 0.80 to $<0.90$.

Research by McDermott et $\mathrm{al}^{32}$ has demonstrated a significant association between impaired

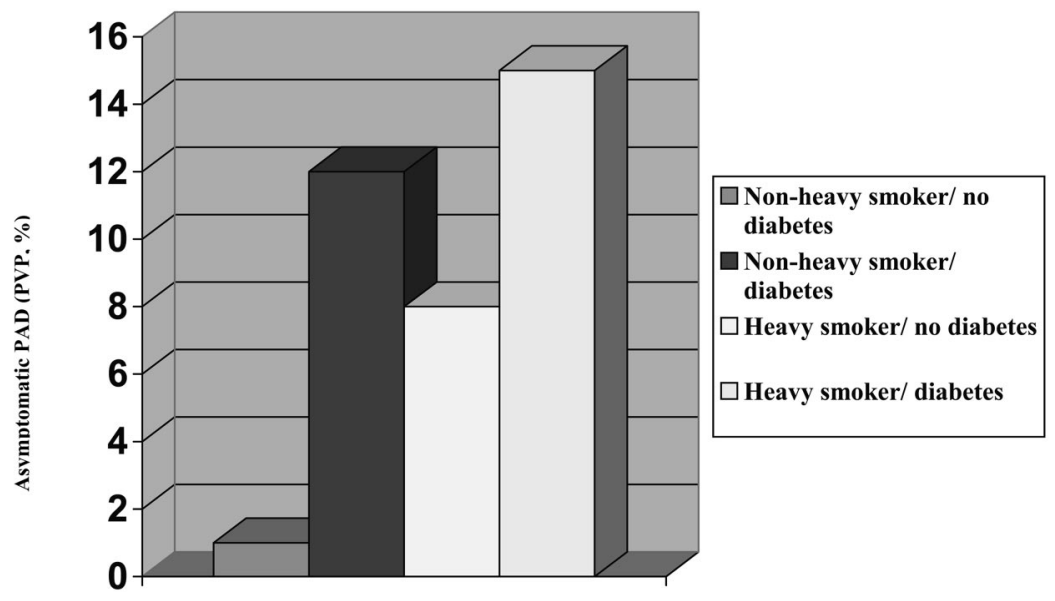

Figure 1. Individual and synergistic associations of diabetes and heavy smoking with asymptomatic PAD. 
lower extremity functioning and asymptomatic $\mathrm{PAD}$. It is possible that functional limitations resulting from poor health could lead to a decrease in physical activity and therefore prevent the symptoms of PAD from occurring. Examining the significant factors associated with asymptomatic PAD in this study and those of previous ones, it can be theorized that screenings among patients who exhibit a risk for PAD could lead to an early detection of the disease, before any symptoms have appeared. This could alert the patient to modify these risk factors and prevent a further progression of the disease to a more serious case.

This study had some limitations. First, the small sample size of 25 patients with asymptomatic PAD could have led to the insignificant results of the other independent variables found in previous studies to have an association with $\mathrm{PAD}$, such as race/ ethnicity, older age, male gender, and history of congestive heart failure and/or hypertension. In addition, a misclassification of leg symptoms could have also occurred. Some patients previously experiencing leg pain on exertion could have limited their physical activity and been misclassified as asymptomatic. Because nearly half the patients (48\%) with asymptomatic PAD rarely or never walked outside for at least 10 minutes without stopping, this could have prevented the manifestation of symptoms, which may not have appeared until much later in the progression of the disease and therefore put the patient at a higher risk for cardiovascular events. Another form of misclassification bias could have been in the recording of the ABI. Calcified arteries, resulting as a complication of diabetes mellitus, could have resulted in a falsely elevated ABI and therefore could have prevented a $\mathrm{PAD}$ diagnosis in a patient with diabetes mellitus. $^{33,34}$

Further research should determine whether the control of diabetes mellitus and/or smoking diminishes the prevalence of asymptomatic PAD in older patients attending a primary care clinic. Several studies have already examined the effects of smoking cessation interventions on patients with symptomatic PAD and have shown that smoking cessation reduces rest pain associated with $\mathrm{PAD}$, decreases the prevalence of myocardial infarction and cardiac death, and increases survival rates. ${ }^{29-33}$ Determining if smoking cessation prevents progression of asymptomatic PAD to intermittent claudication and its subsequent complications might justify the need to screen heavy smokers for PAD.

Further research should look at the effectiveness of screening for PAD in reducing cardiovascular morbidity and mortality. As the population ages, PAD will increase in prevalence, particularly asymptomatic $\mathrm{PAD}$. By examining the effectiveness of $A B I$ and its use with patients at higher risk for $\mathrm{PAD}$, disease may be diagnosed earlier and strategies could be used to delay the progression of the disease and prevent complications.

\section{References}

1. Criqui MH, Fronek A, Barrett-Connor E, Klauber MR, Gabriel S, Goodman D. The prevalence of peripheral arterial disease in a defined population. Circulation 1985;71:510-5.

2. Meijer WT, Grobbee DE, Hunink MG, Hofman A, Hoes AW. Determinants of peripheral arterial disease in the elderly: the Rotterdam study. Arch Intern Med 2000;160:2934-8.

3. Meijer WT, Hoes AW, Rutgers D, Bots ML, Hofman A, Grobbee DE. Peripheral arterial disease in the elderly: the Rotterdam Study. Arterioscler Thromb Vasc Biol 1998;18:185-92.

4. Collins TC, Petersen NJ, Suarez-Almazor M, Ashton CM. The prevalence of peripheral arterial disease in a racially diverse population. Arch Intern Med. 2003;163:1469-74.

5. Hilleman DE. Management of peripheral arterial disease. Am J Health Syst Pharm. 1998;55:21-7S.

6. Hiatt WR, Marshall JA, Baxter J, et al. Diagnostic methods for peripheral arterial disease in the San Luis Valley Diabetes Study. J Clin Epidemiol 1990; 43:597-606.

7. Schroll M, Munck O. Estimation of peripheral arteriosclerotic disease by ankle blood pressure measurements in a population study of 60-year-old men and women. J Chron Dis 1981;34:261-9.

8. Criqui MH, Denenberg JO, Langer RD, Fronek A. The epidemiology of peripheral arterial disease: importance of identifying the population at risk. Vasc Med 1997;2:221-6.

9. Fowkes FG, Housley E, Cawood EH, Macintyre CC, Ruckley CV, Prescott RJ. Edinburgh Artery Study: prevalence of asymptomatic and symptomatic peripheral arterial disease in the general population. Int J Epidemiol 1991;20:384-92.

10. Fowkes FG. Epidemiology of peripheral vascular disease. Atherosclerosis 1997;131(Suppl):S29-31.

11. Aronow WS. Prevalence of atherothrombotic brain infarction, coronary artery disease and peripheral arterial disease in elderly blacks, Hispanics and whites. Am J Cardiol 1992;70:1212-3.

12. Ness J, Aronow WS. Prevalence of coronary artery disease, ischemic stroke, peripheral arterial disease, 
and coronary revascularization in older AfricanAmericans, Asians, Hispanics, whites, men, and women. Am J Cardiol 1999;84:932-3, A7.

13. Newman AB, Siscovick DS, Manolio TA, et al. Ankle-arm index as a marker of atherosclerosis in the Cardiovascular Health Study. Circulation 1993;88: 837-45.

14. Collins TC, Johnson M, Henderson W, Khuri SF, Daley J. Lower extremity nontraumatic amputation among veterans with peripheral arterial disease. Med Care 2002;40(1 Suppl):I106-16.

15. Hooi JD, Kester AD, Stoffers HE, Overdijk MM, van Ree JW, Knottnerus JA. Incidence of and risk factors for asymptomatic peripheral arterial occlusive disease: a longitudinal study. Am J Epidemiol 2001; 153:666-72.

16. McDermott MM, Greenland P, Liu K, et al. Leg symptoms in peripheral arterial disease. JAMA 2001; 286:1599-606.

17. McDermott MM, Mehta S, Greenland P. Exertional leg symptoms other than intermittent claudication are common in peripheral arterial disease. Arch Intern Med 1999;159:387-92.

18. Hirsch AT, Criqui MH, Treat-Jacobson D, et al. Peripheral arterial disease detection, awareness, and treatment in primary care. JAMA 2001;286:1317-24.

19. Hooi JD, Stoffers HE, Kester AD, et al. Risk factors and cardiovascular diseases associated with asymptomatic peripheral arterial disease. The Limburg PAOD study. Peripheral Arterial Occlusive Disease. Scand J Prim Health Care 1998;16:177-82.

20. Walters DP, Gatling W, Mullee MA, Hill RD. The prevalence, detection, and epidemiological correlates of peripheral vascular disease: a comparison of diabetic and non-diabetic subjects in an English community. Diabet Med 1992;9:710-5.

21. Yao ST, Hobbs JT, Irvine WT. Ankle systolic pressure measurements in arterial disease affecting the lower extremities. Br J Surg 1969;56:676-9.

22. Fowkes FG. The measurement of atherosclerotic peripheral arterial disease in epidemiological surveys. Int J Epidemiol 1988;17:248-54.

23. Vogt MT, Cauley JA, Newman AB, Kuller LH, Hulley SB. Decreased ankle/arm blood pressure in- dex and mortality in elderly women. JAMA 1993; 270:465-9.

24. Vogt MT, McKenna M, Anderson SJ, Wolfson SK, Kuller LH. The relationship between ankle-arm index and mortality in older men and women. J Am Geriatr Soc 1993;41:523-30.

25. Collins TC, O'Malley K, Suarez-Almazor M, Petersen N. The Lifestyle and Clinical Survey: validation of a medical history questionnaire. Fed Pract 2005;22:25-6, 29-33, 38-42.

26. Fowkes FG, Housley E, Riemersma RA, et al. Smoking, lipids, glucose intolerance, and blood pressure as risk factors for peripheral atherosclerosis compared with ischemic heart disease in the Edinburgh Artery Study. Am J Epidemiol 1992;135:331-40.

27. Jonason T, Bergstrom R. Cessation of smoking in patients with intermittent claudication. Effects on the risk of peripheral vascular complications, myocardial infarction and mortality. Acta Med Scand 1987;221:253-60.

28. Faulkner KW, House AK, Castleden WM. The effect of cessation of smoking on the accumulative survival rates of patients with symptomatic peripheral vascular disease. Med J Aust 1983;1:217-9.

29. Hughson WG, Mann JI, Tibbs DJ, Woods HF, Walton I. Intermittent claudication: factors determining outcome. Br Med J 1978;1:1377-9.

30. Quick CRG, Cotton LT. The measured effect of stopping smoking on intermittent claudication. Br J Surg 1982;69S:S24-6.

31. Jonason T, Ringqvist I. Factors of prognostic importance for subsequent rest pain in patients with intermittent claudication. Acta Med Scand 1985;218:2733.

32. McDermott MM, Fried L, Simonsick E, Ling S, Guralnik JM. Asymptomatic peripheral arterial disease is independently associated with impaired lower extremity functioning: the women's health and aging study. Circulation 2000;101:1007-12.

33. Kreidy R, Hajjar E. Digital pulse volume recording: an essential test for the assessment of arteritis in diabetic patients. J Med Liban 1997;45:73-7.

34. Edmonds ME. Medial arterial calcification and diabetes mellitus. Z Kardiol 2000;89 Suppl 2:101-4. 